\title{
Defining priorities for improving end-of-life care in Canada
}

\author{
Daren K. Heyland MD MSc, Deborah J. Cook MD MSc, Graeme M. Rocker DM MHSc, \\ Peter M. Dodek MD MHSc, Demetrios J. Kutsogiannis MD MHS, Yoanna Skrobik MD, \\ Xuran Jiang MD MSc, Andrew G. Day MSc, S. Robin Cohen PhD, for the Canadian Researchers \\ at the End of Life Network (CARENET)
}

Previously published at www.cmaj.ca

\section{ABSTRACT}

Background: High-quality end-of-life care should be the right of every Canadian. The objective of this study was to identify aspects of end-of-life care that are high in priority as targets for improvement using feedback elicited from patients and their families.

Methods: We conducted a multicentre, cross-sectional survey involving patients with advanced, life-limiting illnesses and their family caregivers. We administered the Canadian Health Care Evaluation Project (CANHELP) questionnaire along with a global rating question to measure satisfaction with end-of-life care. We derived the relative importance of individual questions on the CANHELP questionnaire from their association with a global rating of satisfaction, as determined using Pearson correlation coefficients. To determine high-priority issues, we identified questions that had scores indicating high importance and low satisfaction.

Results: We approached 471 patients and 255 family members, of whom 363 patients and 193 family members participated, with response rates of $77 \%$ for patients and $76 \%$ for families. From the perspective of patients, high-priority areas needing improvement were related to feelings of peace, to assessment and treatment of emotional problems, to physician availability and to satisfaction that the physician took a personal interest in them, communicated clearly and consistently, and listened. From the perspective of family members, similar areas were identified as high in priority, along with the additional areas of timely information about the patient's condition and discussions with the doctor about final location of care and use of end-of-life technology.

Interpretation: End-of-life care in Canada may be improved for patients and their families by providing better psychological and spiritual support, better planning of care and enhanced relationships with physicians, especially in aspects related to communication and decision-making.

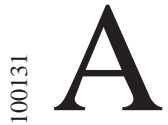

lthough a "quality death" is an espoused right of Canadians, ${ }^{1}$ for many dying patients and their families, it is not achieved. Recent reviews and observational studies describe considerable dissatisfaction with end-of-life care, indicating that there are still opportunities for improvement. ${ }^{2-5}$

Ideally, initiatives aimed at improving end-of-life care would be informed by the experiences and expectations of patients and their family members. However, such efforts are often hampered by inadequate definitions of quality of care and by suboptimal tools for measurement..$^{6-8}$ In a recent, large crosssectional survey, the Canadian Researchers at the End of Life Network defined what matters most to seriously ill patients as they approach the end of life. ${ }^{9}$ Both patients and their family members reported that it was extremely important that they have trust and confidence in the physicians caring for them or their loved ones. ${ }^{9}$ Avoidance of unwanted life-support measures, effective communication, continuity of care, and feelings of life completion were also rated as highly important. ${ }^{9} \mathrm{We}$ used these comprehensive ratings of importance to develop and validate a novel questionnaire to measure satisfaction with endof-life care. ${ }^{10}$ Using this questionnaire, we formally evaluated the care received at the end of life in several Canadian centres.

By targeting initiatives for change at gaps in quality, we can address the highest priorities for improving end-of-life care in Canada. Our objective was to identify high-priority areas for improvement in the care of patients with advanced, life-limiting diseases and in the perceived quality of that care by their families. We identified these areas by focusing on care-related issues that had been rated as important by patients and their family members but were rated low on the questionnaire measuring satisfaction with end-of-life care.

\section{Methods}

\section{Participants}

We conducted a cross-sectional survey involving patients who had advanced, life-limiting illnesses and their family caregivers. Patients and family caregivers were recruited from both inpatient and outpatient facilities and from affiliated home-care pro-

From the Department of Medicine (Heyland) and the Clinical Evaluation Research Unit (Heyland, Jiang, Day), Kingston General Hospital, and the Department of Community Health and Epidemiology (Heyland), Queen's University, Kingston, Ont.; the Departments of Medicine and of Clinical Epidemiology and Biostatistics (Cook), McMaster University, Hamilton, Ont.; the Department of Medicine (Rocker), Queen Elizabeth II Health Sciences Centre, Halifax, NS; the Department of Medicine and the Centre for Health Evaluation and Outcome Sciences (Dodeck), St. Paul's Hospital and University of British Columbia, Vancouver, BC; the Division of Critical Care Medicine (Kutsogiannis), University of Alberta, Edmonton, Alta.; the Division of Critical Care, Hôpital Maisonneuve-Rosemont (Skrobik), Université de Montréal; and the Departments of Oncology and Medicine (Cohen), McGill University and Jewish General Hospital, Montréal, Que.

CMAJ 2010. DOI:10.1503/cmaj.100131 
grams at the Kingston General Hospital in Kingston, Ontario; St. Joseph's Healthcare in Hamilton, Ontario; St. Paul's Hospital in Vancouver, British Columbia; Queen Elizabeth II Health Sciences Centre in Halifax, Nova Scotia; the New Brunswick Extra-Mural Program in Saint John, New Brunswick; Royal Alexandra Hospital in Edmonton, Alberta; and the Hôpital Maisonneuve-Rosemont in Montréal, Quebec.

To be eligible, patients had to understand English or French, be capable of giving informed consent, be older than 55 years of age and meet the clinical criteria for advanced chronic obstructive pulmonary disease, congestive heart failure, liver disease or metastatic cancer. In addition, patients in hospital who were 80 years of age or older were considered eligible if they had a medical diagnosis as the primary reason for admission or if they were enrolled in a home-care program using long-term oxygen therapy and had a primary diagnosis of chronic obstructive pulmonary disease, congestive heart failure or metastatic cancer. A detailed description of the inclusion criteria is shown in Appendix 1, available at www.cmaj.ca/cgi/content/full/cmaj.100131/DC1.

Using clinical judgment, we excluded patients who were cognitively impaired or otherwise unsuitable for administration of a detailed questionnaire because of communication problems or physical or emotional frailty. We obtained written informed consent from willing patients and then asked them to identify a family caregiver. If the patient was not competent or declined involvement, we approached eligible family caregivers independently of the patient's involvement (Appendix 1). The research assistant then conducted separate face-to-face interviews with the patient and with family caregivers and administered the questionnaires described below.

\section{Data collection}

\section{The Canadian Health Care Evaluation Project (CANHELP) questionnaire}

Details of our initial development of the CANHELP questionnaire are published elsewhere. ${ }^{2,9,11,12}$ In brief, we generated items to be included in this questionnaire using a review of the literature, focus groups of experts and interviews with patients. Based on our conceptualization of the major themes emerging from our data, we grouped the items into the following domains: characteristics of the doctors and nurses (8 items), illness management ( 7 items), health service characteristics (4 items), communication and decision-making (11 items), relationships with others (4 items), and spirituality and meaning (3 items). ${ }^{6}$ Before rating the domain-specific items, respondents were asked to rate their overall level of satisfaction with the care they had received in the past month. We developed one version of the questionnaire for patients and two for family caregivers (i.e., one version for use if the patient was alive, and one for use if the patient had died). Options for responses were the following: $1=$ not at all satisfied, $2=$ not very satisfied, $3=$ somewhat satisfied, $4=$ very satisfied and $5=$ completely satisfied. We have shown that the CANHELP questionnaire correlates with other established measures of satisfaction with quality of care at the end of life, has good internal consistency (Cronbach $\alpha>0.70$ ) and can be grouped into valid subscales. ${ }^{10}$
The final version of the questionnaire (available online at www.thecarenet.ca) was used in the current study.

We recorded demographic characteristics of participants at the time of the interview. We assessed patients' functional status using the Palliative Performance Scale. ${ }^{13}$ Comorbidities were categorized and calculated according to the Charlson Comorbidity Index. ${ }^{14}$

\section{Statistical analysis}

We described the characteristics of patients and family caregivers as counts and percentages for categorical variables and as means with standard deviations for continuous variables. Responses to the CANHELP questionnaire were summarized as means with standard deviations (SDs) and ranges. To enable comparisons with previous work using this instrument, we also reported the percentage of respondents who rated themselves as "completely satisfied." To determine the areas that were high in priority as targets for improvement from our data on satisfaction level, we developed plots of importance versus satisfaction. ${ }^{15}$ We defined the relative importance of the items according to their association (as determined by Pearson correlation coefficients) with the global rating of satisfaction. ${ }^{15}$ Items not found to be correlated with overall satisfaction were considered unimportant. Scatter plots were used to assess the relationship between this measure of importance and the mean score on level of satisfaction for each CANHELP question. We used horizontal and vertical grid lines placed at the median of the plotted data points for each measure to identify four separate quadrants. Questions in the upper left quadrant were important (i.e., correlated highly with overall satisfaction) and had the lowest satisfaction scores relative to other questions. We deemed the care-related issues identified by these questions to have the highest priority as targets for improvement. ${ }^{15}$

We obtained approval of the study from the Queen's University Research Ethics Board. The ethics boards of all other participating sites subsequently approved the study.

\section{Results}

From August 2007 to January 2009, 622 patients at participating sites were identified as potentially eligible. Of these, 151 were excluded for reasons related to communication (e.g., inability to understand English or French, inability to speak or hear, or impaired mental status) or unsuitability (i.e., deemed unable to tolerate an interview because of lack of physical stamina or psychological state). Of the 471 remaining eligible patients, 363 consented, for an overall response rate of $77.1 \%$. Two patients withdrew before completing the interview, leaving 361 questionnaires evaluable for analysis. Of the patients who completed the interview, 175 (48.5\%) had an eligible family caregiver available to interview. We also approached 80 family caregivers independently of the nonparticipating patients who met the inclusion criteria, for a total of 255 family caregivers. A total of 193 family caregivers consented, for a response rate of $75.7 \%$.

The demographic characteristics of the patients and family caregivers we included are listed in Table 1. Owing to sporadic missing data, the number of responses used to calculate the average scores for items and the correlation of items with 
the global scores was slightly less than $100 \%$ of the potential total responses for 361 patients and 193 family caregivers. The most frequently missing response was to the item "satisfaction with home care services." A response to this item was missing in the questionnaire results for $60(16.6 \%)$ patients and $33(17.1 \%)$ caregivers. In both questionnaires, all other items were completed by at least $93.3 \%$ of respondents.

\section{Patients}

The Pearson correlation coefficients showing the association between the scores on individual items and the global satisfaction rating, and the percentage of respondents who indicated for each question that they were completely satisfied, are listed in Appendix 2 (available at www.cmaj.ca/cgi/content/full/cmaj $.100131 / \mathrm{DC} 1)$. Using the magnitude of the correlation coefficients to determine importance, we identified the following as the five most important issues from the perspective of patients: being treated by doctors and nurses in a manner that preserved the patient's sense of dignity (Pearson $r=0.46, p<0.001$ ), receiving good care when a family member or friend was not able to be with them ( $r=$ $0.42, p<0.001)$, aspects of their medical care (e.g., tests that were done and treatments given) ( $r=0.41, p<0.001)$, that health care workers worked together as a team to look after them $(r=0.41$, $p<0.001)$ and that the doctors and nurses looking after them were compassionate and supportive $(r=0.41$, $p<0.001)$.

The mean score for the global rating of satisfaction was 4.3 (SD 0.8, range 1.0-5.0). Patients were least satisfied with the following issues: doing special things they wanted to do during the past month (mean score 3.08), their level of confidence in their own ability to manage their illness (3.18), their understanding of what to expect in the end stage (3.41), their ability to contribute to others (i.e., help other people) in a meaningful way (3.52), and discussions with their physician about final location of care (3.65) and use of life-sustaining technology at the end of life (3.67) (Appendix 1).

The relationship between the importance-related scores and the mean satisfaction-related scores for each question is
Table 1: Demographic characteristics of study participants

\begin{tabular}{|c|c|c|}
\hline Characteristic & $\begin{array}{l}\text { Patients, no. }(\%)^{*} \\
n=361\end{array}$ & $\begin{array}{c}\text { Caregivers, no. }(\%)^{*} \\
n=193\end{array}$ \\
\hline Age, yr, mean (SD) & $76.6(9.9)$ & $61.9(13.3)$ \\
\hline Sex, female & $175(48.5)$ & $144(74.6)$ \\
\hline \multicolumn{3}{|l|}{ Location of interview } \\
\hline Home or retirement home & $81(22.4)$ & $62(32.1)$ \\
\hline Hospital & $256(70.9)$ & $114(59.1)$ \\
\hline Palliative care unit & $24 \quad(6.7)$ & $14(7.3)$ \\
\hline $\begin{array}{l}\text { Long-term care or nursing } \\
\text { home }\end{array}$ & 0 & $1(0.5)$ \\
\hline Other & 0 & $2(1.0)$ \\
\hline \multicolumn{3}{|l|}{ Ethnicity } \\
\hline White & $313(86.7)$ & $162(83.9)$ \\
\hline Aboriginal & $36(10.0)$ & $22(11.4)$ \\
\hline East Asian or Pacific islander & $4(1.1)$ & $5(2.6)$ \\
\hline African or black North American & $5(1.4)$ & $1(0.5)$ \\
\hline South Asian & $1(0.3)$ & 0 \\
\hline Other & $2(0.6)$ & $2(1.0)$ \\
\hline Unknown & 0 & $1(0.5)$ \\
\hline \multicolumn{3}{|l|}{ Education } \\
\hline Elementary school or less & $50(13.9)$ & $7(3.6)$ \\
\hline Some high school & $118(32.7)$ & $29(15.0)$ \\
\hline High school diploma & $80(22.2)$ & $43(22.3)$ \\
\hline Some college or trade school & $36(10.0)$ & $23(11.9)$ \\
\hline College diploma or trade school & $30(8.3)$ & $39(20.2)$ \\
\hline Some university & $15(4.2)$ & $8(4.1)$ \\
\hline University degree & $21(5.8)$ & $27(14.0)$ \\
\hline Postgraduate degree & $8(2.2)$ & $11(5.7)$ \\
\hline Other & 0 & $4(2.1)$ \\
\hline Unknown & $3(0.8)$ & $2(1.0)$ \\
\hline \multicolumn{3}{|l|}{ Primary eligibility criteria met } \\
\hline Age $\geq 80 \mathrm{yr}$ & $97(26.9)$ & \\
\hline $\begin{array}{l}\text { Chronic obstructive pulmonary } \\
\text { disease }\end{array}$ & $128(35.5)$ & \\
\hline Heart failure & $50(13.9)$ & \\
\hline Cirrhosis & $5(1.4)$ & \\
\hline Cancer & $81(22.4)$ & \\
\hline \multicolumn{3}{|l|}{ Relative being cared for by caregiver } \\
\hline Husband, wife or partner & & $94(48.7)$ \\
\hline Parent & & $69(35.8)$ \\
\hline Parent-in-law & & 7 (3.6) \\
\hline Daughter or son & & $3(1.6)$ \\
\hline Sister or brother & & $5(2.6)$ \\
\hline Other & & $12(6.2)$ \\
\hline Unknown & & $2(1.0)$ \\
\hline $\begin{array}{l}\text { Score on Palliative Performance Scale, } \\
\text { mean (SD) }\end{array}$ & $60.2(15.8)$ & \\
\hline Charlson Comorbidity Index, mean (SD) & $2.7 \quad(2.3)$ & \\
\hline
\end{tabular}

Note: SD = Standard deviation.

*Unless otherwise indicated. 
shown in Figure 1. The issues deemed to have the highest priority were localized to the upper left quadrant, and were related to patients' feelings of peace, the availability of their doctor, the assessment and treatment of their emotional problems, whether their doctor took a personal interest in them and listened to them, the consistency of information about their conditions from all doctors and nurses, and whether things were explained in a way they could understand (Table 2).

\section{Family caregivers}

The mean global rating of satisfaction by family caregivers with how they were treated was 4.2 (SD 0.8, range 1.0-5.0). The importance-related and satisfaction-related scores for each question on the family caregiver satisfaction survey are shown in Appendix 3 (available at www.cmaj.ca/cgi/content/full /cmaj.100131/DC1). The performance-importance plots of data representing the perspective of family caregivers are shown in Appendix 4 (available at www.cmaj.ca/cgi/content /full/cmaj.100131/DC1). Issues that were high in priority from the perspective of family caregivers are itemized in Table 2.

\section{Interpretation}

In our study involving 361 seriously ill patients and 193 family members in several health care centres, we documented that overall satisfaction with end-of-life care was good. (The overall score on this scale of 1-5 was 4.3 for patients and 4.1 for family members.) However, these results should not be interpreted as suggesting that there are no areas in which end-of-life care for this population can be improved. Respondents of surveys of satisfaction tend to over-report positive responses. ${ }^{16}$ Among individual patients and their families and in responses on specific aspects of care, there were many ratings of dissatisfaction; the proportion of respondents rating

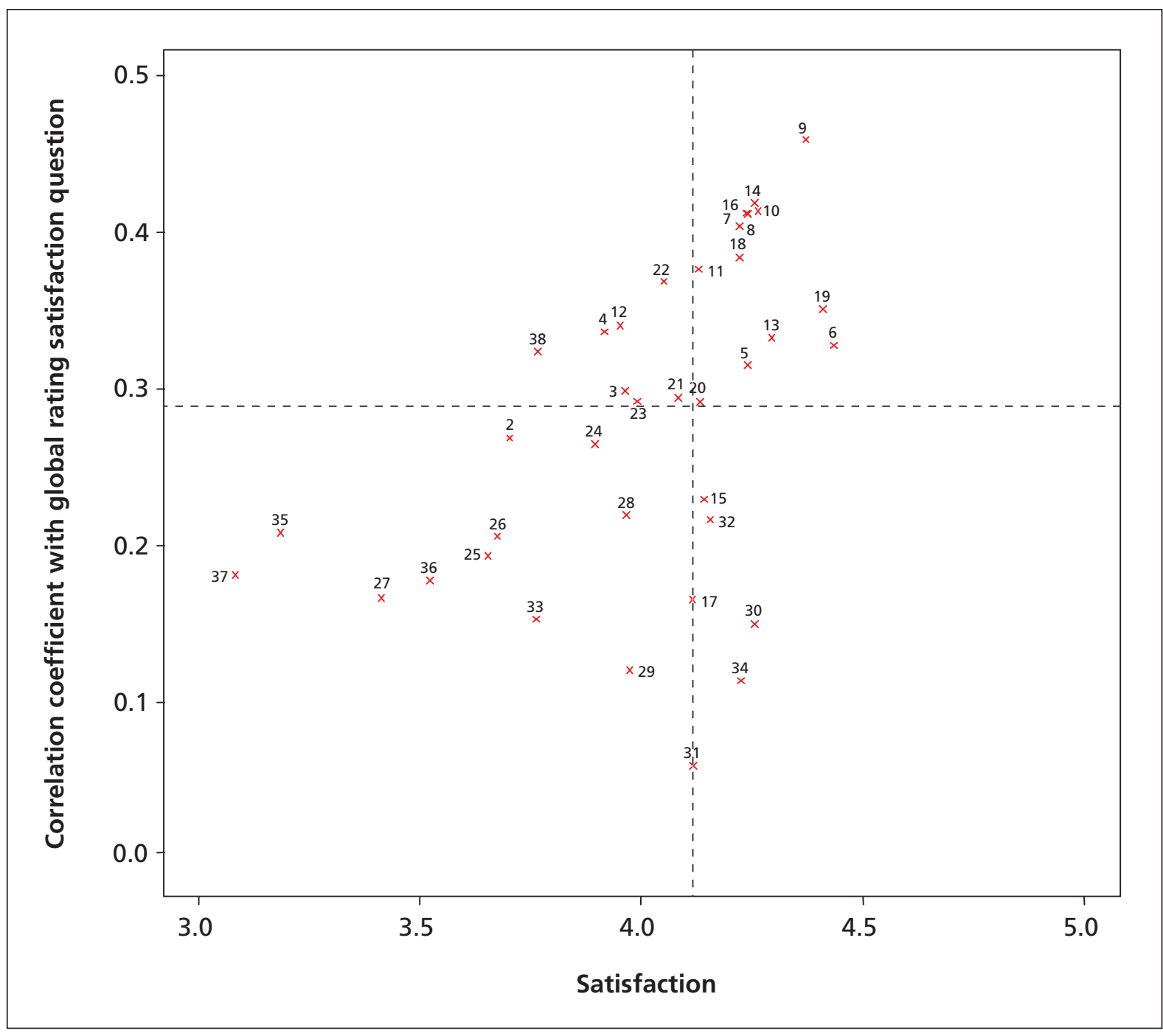

Figure 1: The performance-importance grid, as derived from a plot of the mean score for each question on the Canadian Health Care Evaluation Project (CANHELP) questionnaire for patients (measuring satisfaction with care) and the correlation coefficient for each question's association with overall satisfaction from the patient's point of view. Gridlines correspond to the median of the mean scores on each question (4.12) and the median of the correlation coefficients (0.29). Note: $x=$ the plotted value; the number closest to the $x$ is the corresponding CANHELP question number. 
themselves as completely satisfied was as low as $9 \%$ and only as high as $57 \%$.

We assessed the extent to which each question was associated with a global rating of satisfaction so that quality improvement initiatives can be focused on issues that matter most to patients. We found that being cared for while experiencing preservation of dignity, being treated with respect and compassion, having trust and confidence in one's doctor, and being well looked after by one's health care team are all important aspects of good-quality end-of-life care. These findings are consistent with those of studies involving other populations and reporting similar aspects of care as being important at the end of life.,17-19

For both patients and families, the areas needing improvement that were highest in priority were the emotional support provided to patients, the quality of the relationship of the doctor with the patient and patient's family, and communication and decision-making. Deficiencies in relationships with physicians and in communication and decision-making have been highlighted previously., ${ }^{2,20}$ In our findings, these deficiencies were centred on physicians' attentiveness, frequency and consistency of interactions with patients and their fami- lies, and planning of the logistics of end-of-life care, including limitations on life-sustaining therapies. These gaps did not appear related to medical aspects of care; satisfaction with tests and treatments was rated very high by patients.

Whereas high levels of anxiety and depression have been reported previously among patients with cancer, ${ }^{24,25}$ we found that there is a large unmet need for emotional support among patients with advanced medical diseases and their families. This finding underscores the need to improve the assessment and treatment of symptoms of depression and anxiety in this population. Our identification of being at peace as a high-priority issue for improvement is consistent with reports from other studies that existential and spiritual concerns are very prevalent at the end of life. ${ }^{26,27}$ Although being at peace did not have the same importance to family caregivers in our survey, evidence from a longitudinal study ${ }^{11}$ suggests that this issue is also relevant to family members, whose satisfaction with issues related to their own spirituality and sense of meaning were found to deteriorate substantially in the months after the death of a loved one. We hypothesize that a psychologically or spiritually supportive intervention may help to improve satisfaction with end-of-life care. ${ }^{28}$

Table 2: Questionnaire items that were high in importance based on responses from patients and their families

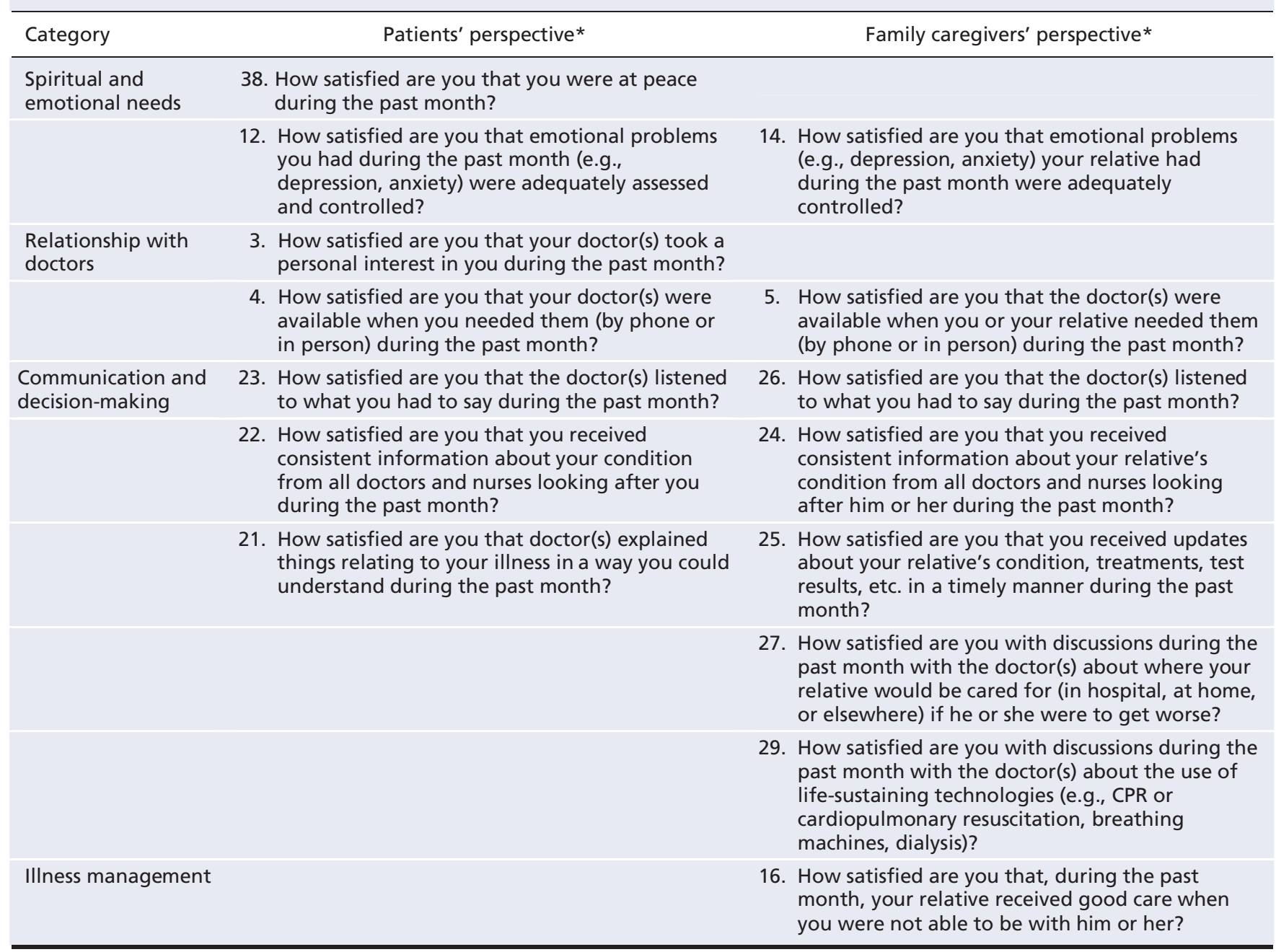

*Numbers shown are the question numbers on the corresponding version of the questionnaire (i.e., patient version or family caregiver version). 


\section{Limitations}

The limitations of this study are related to the fact that we did not measure importance directly. Asking patients directly to rate the level of importance of each question would have seriously compromised the feasibility of this study by adding to the burden of data collection. In this analysis, we used median scores to identify thresholds on the performance-importance grids. Depending on the institutional resources available, the threshold for these lines could be set elsewhere to identify issues for improvement. Alternatively, institutions could select among items outside of the upper left quadrant to focus on. Although there is no single approach to prioritizing these gaps in quality of care, we suggest that such heuristic divisions provide a useful starting point. Moreover, given the cross-sectional nature of this study, we cannot be certain whether dissatisfaction with care leads to emotional distress or whether emotional distress leads to dissatisfaction with care. Furthermore, we have used the CANHELP questionnaire as a screening tool. Although responses to it may illuminate in general terms where problems lie, more detailed assessments will be required in some cases to understand specific unmet needs. Finally, our study sample primarily comprised a white population; there may be other ethnic groups of patients to which our results do not apply. To overcome this deficiency, we have developed a version of the CANHELP questionnaire that enables individual patients and family caregivers to rate each aspect of care both on its importance and their satisfaction. This version (available at www.thecarenet.ca) allows us to derive a prioritized list of quality-improvement targets individualized to a given patient or patient's family. The strengths of our study include our use of a validated questionnaire and our focus on patients in multiple settings who had diverse medical conditions.

\section{Conclusion}

We have identified, from the perspective of patients with advanced, life-limiting diseases and their family members, aspects of care that are high in priority as targets for improvement and that may have the greatest impact in improving overall end-of-life care if so targeted. Psychological interventions, spiritual support, better planning of care, improvements in the nature of physicians' relationships with patients and with patients' families, and enhancement of specific aspects of communication and decision-making could help dying patients and their families realize their right to high-quality care at the end of patients' lives.

This article has been peer reviewed.

\section{Competing interests: None declared.}

Contributors: Daren Heyland, Andrew Day, Xuran Jiang and Robin Cohen designed the study protocol with input from other co-investigators. Daren Heyland, Deborah Cook, Graeme Rocker, Peter Dodek, Demetrios Kutsogiannis and Yoanna Skrobik participated in the acquisition, analysis and interpretation of the data and the writing of the manuscript. Xuran Jiang, Andrew Day and Robin Cohen were responsible for the analysis of the data and critically reviewed the manuscript. All of the authors approved the final version of the manuscript submitted for publication.

Acknowledgements: The authors thank all of the members of the Canadian Researchers at the End of Life Network (CARENET) for their contributions to the evolution and development of this work, and the following research assistants who helped in the development of the questionnaire and execution of the study: Deborah Pichora, Jennifer Korol, NancyPaul, Sheilagh Mans, Joanne Young, Wendy Conrad, Pat Thompson, Melissa TeBrake, Chantal Tessmer and Janice Palmer.
Funding: This study was supported by CARENET. CARENET is supported by a grant from the Canadian Institutes of Health Research and the Heart and Stroke Foundation of Canada.

Deborah Cook holds a Canada Research Chair with the Canadian Institutes of Health Research.

\section{REFERENCE}

1. Carstairs S, Beaudoin GA. Quality end of life care: the right of every Canadian. Ottawa (ON): Senate of Canada; 2000. Available: www.parl.gc.ca/36/2/parlbus /commbus/senate/com-e/upda-e/rep-e/repfinjun00-e.htm (accessed 2010 July 8).

2. Heyland DK, Groll D, Rocker G, et al.; Canadian Researchers at the End of Life Network (CARENET). End of life care in acute care hospitals in Canada: A quality finish? J Palliat Care 2005;21:142-150.

3. Carstairs S. Still not there. Quality end-of-life care: a progress report. Ottawa $(\mathrm{ON})$ : Senate of Canada; 2005. Available: http://sen.parl.gc.ca/scarstairs/PalliativeCare /PalliativeCare_e.asp (accessed 2010 July 8).

4. Workman S, Mann OE. "No control whatsoever": end-of-life care on a medical teaching unit from the perspective of family members. QJM 2007;100:433-40.

5. Giles S. Palliative stage Parkinson's disease: patient and family experiences of health-care services. Palliat Med 2009;23:120-5.

6. TIME: Toolkit of Instruments to Measure End-of-life care. Satisfaction with quality of care. Providence (RI): Brown University; 2002. Available: www.chcr.brown .edu/pcoc/satisfac.htm (accessed 2010 July 8).

7. Lo B. Improving care near the end of life. Why is it so hard? JAMA 1995;274:1634-6.

8. Mularski RA, Dy SM, Shugarman LR, et al. Systematic review of measures of end-of-life care and its outcomes. Health Serv Res 2007;42:1848-70.

9. Heyland DK, Dodek P, Rocker G, et al. Canadian Researchers at the End of Life Network (CARENET). What matters most in end-of-life care: perceptions of seriously ill patients and their family members. CMAJ 2006;174:627-33.

10. Heyland DK, Cook D, Rocker G, et al. The development and validation of a novel questionnaire to measure patient and family satisfaction with end-of-life care: the Canadian Health Care Evaluation Project (CANHELP) Questionnaire. J Palliat Care. 2010 Jul 6. [Epub ahead of print].

11. Heyland DK, Frank C, Tranmer J, et al.; Satisfaction with end of life care: a longitudinal study of patients and their family caregivers in the last months of life. $J$ Palliat Care 2009;25:245-56.

12. Heyland DK, Cohen R, Skrobik Y, et al. Content validity and acceptability of "CANHELP" satisfaction instruments for French speaking patients with end-stage medical disease or metastatic cancer. J Palliat Care 2006;22:153.

13. Anderson F, Downing GM, Hill J, et al. Palliative performance scale (PPS): a new tool. J Palliat Care 1996;12:5-11.

14. Charlson ME, Pompei P, Ales KL, et al. A new method of classifying prognostic comorbidity in longitudinal studies: development and validation. J Chronic Dis 1987; 40:373-83

15. Dodek PM, Heyland DK, Rocker G, et al. Translating family satisfaction data into quality improvement. Crit Care Med 2004;32:1922-7.

16. Ingram BL, Chung RS. Client satisfaction data and quality improvement planning in managed mental health care organizations. Health Care Manage Rev 1997;22:40-52.

17. Goodridge D, Bond JB, Cameron C, et al. End of life care in a nursing home: a study of family, nurse, and health care aide's perspectives. Int J Palliat Nurs 2005;11:226-32.

18. Vohra JU, Brazil K. Hanna, Abelson J. Family perceptions of end of life care in long-term care facilities. J Palliat Care 2004;20:297-302.

19. Chochinov HM, Krisjanson L, Hack T, et al. Dignity in the terminally ill: revisited. J Palliat Med 2006;9:666-72.

20. Hanson LC, Danis M, Garrett J. What is wrong with end of life care? Opinions of bereaved family members. J Am Geriatr Soc 1997;45:1339-44.

21. Curtis JR, Patrick DL, Engelberg RA, et al. A measure of the quality of dying and death: Initial validation using after-death interviews with family members. J Pain Symptom Manage 2002;24:17-30.

22. Malacrida R, Bettelini CM, Degrate A, et al. Reasons for dissatisfaction: a survey of relatives of intensive care unit patients who died. Crit Care Med 1998;26:1187-93.

23. Kuhl D. What dying people want: practical wisdom for the end of life. Toronto (ON): Doubleday Canada; 2002

24. Breitbart W, Bruera E, Chochinov H, et al. Neuropsychiatric syndromes and psychological symptoms in patients with advanced disease. J Pain Symptom Manage 1995; 19:131-41.

25. Kissane DW, Breitbart W, Prigerson HG. Do rates of mental disorders and existential distress among advanced stage cancer patients increase as death approaches? Psychooncology 2009; 18:50-61.

26. Greisinger AJ, Lorimor RJ, Aday LA, et al. Terminally ill cancer patients: their most important concerns. Cancer Pract 1997;5:147-54.

27. Bolmsjö I. Existential issues in palliative care: interviews of patients with amyotrophic lateral sclerosis. J Palliat Med 2001;4:499-505.

28. LeMay K, Wilson KG. Treatment of existential distress in life threatening illness: a review of manualized interventions. Clin Psychol Rev 2008;28:472-93.

29. O'Donnell DE, Aaron S, Bourbeau J, et al. Canadian Thoracic Society recommendations for management of chronic obstructive pulmonary disease - 2007 update. Can Respir J 2007;14(Suppl B):5B-32B.

Correspondence to: Dr. Daren K. Heyland, Angada 4, Kingston

General Hospital, Kingston ON K7L 2V7; dkh2@queensu.ca 